\title{
COMPARISON OF QUALITY OF LIFE OF PATIENTS WITH LOCAL DISTRIBUTED BREAST CANCER FORMS AFTER CHEMOTHERAPY IN REGIONAL AND SYSTEM REGIMES
}

\author{
Yuriy Dumanskiy \\ Department of the oncology and radiology \\ Donetsk medical university \\ 27 Pryvokzalna str., Liman, Donetsk region, 84404 \\ oncologdopc@gmail.com \\ Oleksandr Bondar \\ Department of surgery No. 4 with oncology \\ Odessa National Medical University \\ Heard of the mammology department \\ University clinic of Odessa medical university \\ 8 Tinista str., Odessa, Ukraine, 65009 \\ Oleksandr Tkachenko \\ Department of surgery No. 4 with oncology \\ Odesa state medical university \\ 2 Valikhovskiy lane, Odessa, Ukraine, 65082 \\ doctortkachenko@i.ua \\ Evhenii Stoliachuk \\ Department of the surgical \\ University clinic of Odessa National Medical University \\ 8 Tinista str., Odessa, Ukraine, 65009 \\ engenes100@gmail.com \\ Vasilii Ermakov \\ Department of the surgical \\ University clinic of Odessa National Medical University \\ 8 Tinista str., Odessa, Ukraine, 65009 \\ vacatrial1994@icloud.com
}

\footnotetext{
Abstract

For several decades, breast cancer (BC) undoubtedly ranks first in the structure of oncopathology and is the most common cause of the loss of working capacity of the female population in most countries. Considering the increasing quality of care for patients with breast cancer, there is the need for standardization and implementation of methods to assess not only quantitative but also qualitative component of a comprehensive opinion on the results of therapy. Therefore, an important indicator to be taken into account is the quality of life (QL) of a patient.

Definition of QL of patients with inoperable forms of locally advanced breast cancer before and after neoadjuvant courses of systemic polychemotherapy (SPCT) and selective intra-arterial polychemotherapy in combination with systemic (SIAPCT).

154 patients with LA BC T4A-DN0-3M0, who received comprehensive treatment on the basis of the Donetsk regional antitumor center and the University clinic of the Odessa National Medical University during the period from 2000 to 2017 , who received SPCT or SIAPCT as a neoadjuvant course, were included in the study.

According to the quality of life during the treatment period, wavelike dynamics with a clear advantage of selective intra-arterial polychemotherapy over the system was observed. According to the quality of health between groups, the marginal statistically significant difference in favour of regional PCTs was formed.

In a detailed study of each of the options found stable symptomatic scale dependent components of the integral index of quality of life on the severity and duration of intoxication syndrome. On the basis of the results obtained, the statistical advantage of the RMRM remains with the regional PCT.
} 
The QL study is a reliable, informative and economical method for assessing the health status of the patient, both at the group and at the individual level. In cancer studies, the evaluation of QL is an important criterion for assessing the effectiveness of treatment and has a prognostic value.

Keywords: locally advanced breast cancer, complex treatment, intra-arterial polychemotherapy, systemic polychemotherapy, quality of life.

\section{Introduction}

During the last decades of the last century and at the beginning of the current cancer-registry of most countries have been continuously diagnosing breast cancer (BC) as the most common cancer and one of the most common causes of disability and mortality among the female population of the world [1]. To date, the etiological search for this pathology has come down to a fairly wide range of causes, none of which can be definitely identified as the main one. At the same time, pathogenetically and morphologically, breast cancer itself is a fairly conventional name for a distinct spectrum of neoplasia, different from genetic and immunohistochemical properties [2]. According to WHO, the epidemiological map clearly traces the tendency of its greatest prevalence among the population of developed countries, with a different percentage of probability associated with the cultural, traditional and social features of the Western world [3]. Despite the constant progress of medicine, new advances in the development of its general and special directions, as well as the tireless and close attention of the public to the problem of breast cancer, statistical data on a scale of decades do not show convincing qualitative changes in the dynamics of morbidity and mortality $[4,5]$. All this naturally determines the need to increase the costs of maintaining and improving diagnostic, treatment and rehabilitation measures by insurance companies and the growing equity of clinical and academic interest in understanding the key aspects of $\mathrm{BC}[6,7]$.

In recent years, approaches and protocols for diagnosis, treatment and rehabilitation of patients with BC have changed significantly for different age groups and for different clinical situations. However, there is still a tendency to assess the effectiveness of the treatment performed on the basis of objective intensive and extensive statistical indicators of overall survival, duration of a non-recurring period and disability. Historical approaches to the most radical intervention, typical of most of the last century, are currently undergoing staged processes of viewing and comparing $[8,9]$. With the advent of the concept of evidence-based medicine and the beginning of the formation of an international evidence base in the world of medical community come to the conclusion of the irrationality of many classical methods of treatment and accepted methods for assessing the results [10]. Therefore, taking into account the increasing quality of care to patients with $\mathrm{BC}$, the question arises of the need for standardization and the introduction of methods for assessing not only the quantitative but also qualitative component of the comprehensive conclusion on the results of therapy. Therefore, an important indicator to be taken into account is the quality of life (QL) of a patient [11, 12].

In the index of IndexMedicus (1977), QL is defined as the physical, emotional, financial and spiritual well-being of man [13]. According to the decision of the American Society of Clinical Oncology (ASCO), QL is more important than the level of non-recurrent survival in evaluating the results of antitumor therapy [14].

The main advantage of the QL index is its integrative property: it can combine a number of non-parametric characteristics, such as the general functional state of the organism, its physical, psychological-emotional and socio-cognitive aspects, as well as subjective symptoms, that is, to be able to evaluate the state of the organism before and after the intervention from the point of view of the patient, and then rationalize the further therapeutic tactics. In essence, this indicator is an asymptotically objective estimate of subjective data.

However, the nature of the QL index remains subjective, which determines the general problem of its use: the absence of output baselines and their reference values, the complexity of the di- 
rect application of modern statistical methods of information processing, the use as a scientific and methodological material of visual-analog scales and questionnaires, therefore the composition and the sequence of questions which is in a state of constant change under the influence of the results of research evidence-based medicine.

Today's comprehensive assessment questionnaires still retain a number of disadvantages associated with quantitative and qualitative recalculation, but allow to develop and structure the material for further processing and create new scientific and methodological materials on the basis of feedback. In foreign literature, the problem of the definition and use of qualitative indicators in general is highlighted broadly, which is due to the above-mentioned factors. In domestic sources, the issue of the psychological state of women is most fully solved only in the context of obvious psychological deviations: stress disorders, anxiety, depression.

Modern medicine is patient oriented, on its needs, interests and experiences. Therefore, the subjective parameters of the evaluation of treatment outcomes must be taken into account in the integrated approach to the planning of intervention tactics along with objective considerations [15].

Despite the high level of interest of a large number of researchers in influencing the different methods of treatment of locally advanced forms of breast cancer (LA BC) on the state of health and quality of life of the patient before and after the intervention, the number and extent of research in this direction in our country remains unconvincing. The problem of inoperable forms of LA BC is very relevant, since patients with this pathology usually receive systemic polychemotherapy (SPCT), which in most cases gives an unsatisfactory therapeutic effect and translates them into a group of cancer patients receiving symptomatic therapy.

Regional methods of SPCT (intra-arterial, intravenous, endolymphatic) are one of the modern surgical ways of solving the question of a selective approach to the treatment of malignant neoplasms. In general, the essence of selective intra-arterial polychemotherapy (SIAPCT) consists in catheterization of the internal chest artery on the side of the localization of formation and isolated potentiated perfusion of the affected area by CT preparations [16, 17]. Radical distinctive features of the system approach are two parameters: increasing the effectiveness of treatment and reducing the negative side effects of cytotoxic drugs on the human body. As a result of the analysis, the following data were determined: reduction of the total effect on the target organs (control of cytological and biochemical parameters of blood), improvement of treatment efficiency: reduction of the proportion of tumours that acquired the status of operability after the intervention $[18,19]$. Prevention of associated complications, such as tumour expansion, tumour metastasis, tumour disintegration, development of intoxication syndrome, anorexia bleeding, secondary infection attachment; an increase in the proportion of radical surgical interventions; reduced physical recovery period; increasing the psychological and emotional level of the patient and increasing compliance with the doctor and the institution, which improves the results of treatment and levels of individual and collective health of the population [20,21].

\section{Aim of the research}

Definition of QL of patients with inoperable forms of LA BC before and after neoadjuvant courses of systemic polychemotherapy (SPCT) and selective intra-arterial polychemotherapy (SIAPCT).

\section{Materials and methods}

The study involved 154 patients with LA BC $\mathrm{T}_{4 \mathrm{~A}-\mathrm{D}} \mathrm{N}_{0-3} \mathrm{M}_{0}$, who received comprehensive treatment on the basis of the Donetsk regional antitumor center and the University clinic of the Odessa National Medical University during the period from 2000 to 2017, who were asked to complete a questionnaire at various stages of the preoperative treatment. The sample was standardized according to age and clinical parameters. Age range: [28-74 years], average age -54.2 years. Among the patients, 120 (78\%) belonged to the able to work age group. The first group, defined as control, included 65 patients (42\%) with inoperable forms of LA BC, which was performed as a neoadjuvant course by the SPCT. The second group (the study population) included 89 patients $(58 \%)$ with inoperable forms of LA BC, which was carried out as neoadjuvant course SIAPCT. 
The number of courses undergoing preoperative PCT was on average 2 to 4 . All participants in the experiment gave a written voluntary consent to participate in the study in accordance with the WMA Declaration of Helsinki Ethical Principles for Medical Research Involving Human Subjects, 2013).

The ultimate goal is to convert the tumour from an inoperable state to a state in which it is possible to carry out a radical amount of surgical intervention.

The study of the quality of life of patients was conducted within the framework of the International Protocol of the European Organization for the Research and Treatment of Cancer, using questionnaires of the European Organization for the Research and Treatment of Cancer (EORTC QLQ-C30), which have been tested in numerous foreign studies and meet the criteria for reliability, validity and effectiveness.

In the used version of the questionnaire, 30 questions are divided into groups: general questions (quality of life (QL) and quality of health $(\mathrm{QH})$ ), scale of functional status (physical, emotional, role, social and cognitive) and scale of symptoms. The answers to the questions were subjected to linear transformation, resulting in the reference values of the results, which were placed in the points range [1-100]. For functional scales, 0 scores had the results that corresponded to the worst scores, and 100 scores were the best. For symptomatic scales 0 points were assigned the smallest manifestation of the symptom, 100 points - the largest.

The study of the dynamics of QL in patients with breast cancer, depending on the type of specific antitumor effect, was carried out at the following stages of treatment:

1) QL in patients before specific antitumor treatment;

2) QL in patients after a neoadjuvant course of SPCT;

3) QL in patients after a neoadjuvant course of SIAPCT in combination with systemic.

Patient questioning was carried out immediately before the start of PCT (within 1 week) and 10-14 days after the first, second, third and fourth PCT courses. These control points were identified as optimal for evaluating functional and symptomatic variables. The questionnaire was conducted among $100 \%$ of the subjects of both groups at an initial stage and stopped after reaching the resectable state of the tumor.

Protocol for the use of the CAMF scheme in the mode of selective intra-arterial polychemotherapy:

- Cyclophosphan: first, fourth, seventh day - $600 \mathrm{mg}$;

- Methotrexate: second, fifth, and eighth day intravenously $-10 \mathrm{mg} / \mathrm{h}$;

- Doxorubicin: the ninth day intravenously - $80 \mathrm{mg}$;

- Fluorouracil: the third day $-800 \mathrm{mg}$, the sixth, the ninth day $-600 \mathrm{mg}$ [21].

Total course doses of chemotherapy were calculated according to BSA criteria.

Data processing was performed using standard statistical functions of the MS Excel program. When comparing the parameters of QL in the study groups, the nonparametric index is used - the Pearson $\mathrm{X}^{2}$ coefficient, and the growth indices for studying dynamics. Static comparison parameters: estimated value of degree of freedom $=1 ; p$-level $=0.05 ; \chi^{2}=3.841$ ).

\section{Results}

The general condition of patients before the neoadjuvant chemotherapy was due to objective (presence of tumour neoplasms and their complications: intoxication syndrome, syndrome of tumour decay, adherence of secondary infection) and subjective (psychological and emotional) factors. In this case, the quality of life indicator (Fig. 1) did not differ significantly in the control group ( $54 \pm 11.3$ points) and the study group (51 \pm 7.4 points) (at $\rho=0.05, \chi^{2}=0.18$ ).

After completing 2 courses of chemotherapy, the QL score decreased in both groups by $11.1 \%$ ( $46 \pm 4.3$ points) in the first group, by $5.9 \%$ (48 \pm 5.0 points) in the second, but the difference remained statistically insignificant. Among the patients in the control group, 3 (4.6\%) developed a severe intoxication syndrome, after which they refused to further participate in the study. According to the authors, the negative dynamics is associated with the absence of an obvious subjective improvement of the state, the absence of expected reduction of the size of the tumour by the patients, and the maintenance of the intoxication syndrome. The ultimate goal was achieved 
in $16(25 \%)$ patients in the first group and in $41(46 \%)$ of the second. After the third course of chemotherapy, the determination of patients with the studied parameter increased by $13 \%$ ( $52 \pm 2.3$ points) in the control group and by $42 \%$ (68 \pm 3.7 points) in the study group as a result of the positive evaluation of patients with their own general condition, the state of the tumour and the achievement of the expected result in themselves and other study participants. At this stage, convincingly reliable data were obtained in favour of regional PCT (with $\mathrm{p}=0.05$, the $\chi^{2}$ index $=5.333$ ). Resectable tumour status was achieved in 30 (46 \%) women in the first group and in 39 (44\%) of the second. After 4 courses of PCT, the rates decreased by two to four points in both groups (50 \pm 4.4 and $64 \pm 2.3$ points respectively), which is explained by the depletion of patients and their dissatisfaction with the systematic deterioration of the state after each administration of the drugs. Nonetheless, the statistical difference in favour of SIAPCT remained significant $\left(\chi^{2}=3.998\right)$. Clinical effects appeared in 17 (26\%) women in the control group and $9(10 \%)$ in the second. Unfortunately, the resectable state of LA BC did not reach in 2 (3\%) patients of the first group; they were proposed a system of professional assistance and support for cancer patients and symptomatic therapy in an oncologic dispensary.

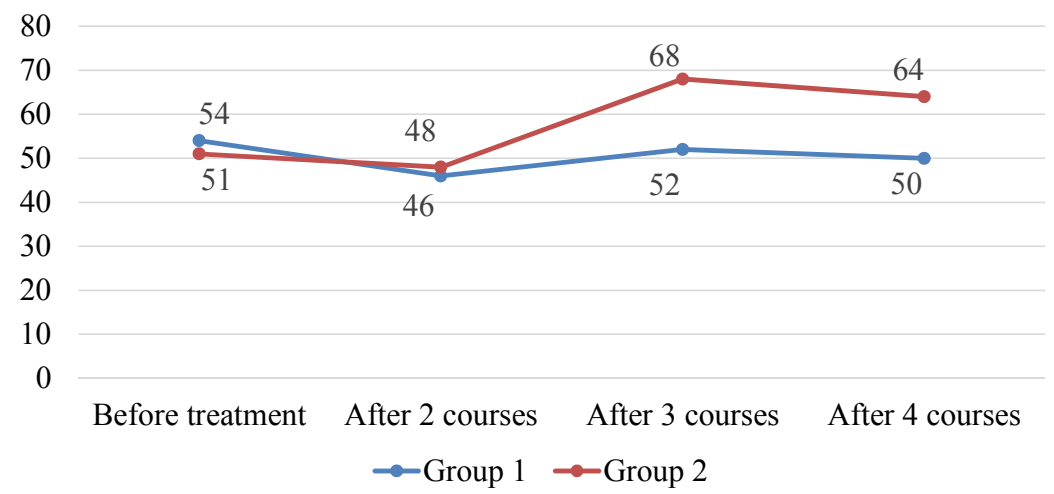

Fig. 1. Patients QL before and after SPCT and SIAPCT

Considering another indicator of the general nature - the quality of health (Fig. 2) - was observed an excellent dynamics. Before the chemotherapy between the study and control groups, the following values were obtained: on average, the health of the patient in 1 group was estimated at $32 \pm 4.1$ points, the second group patients - by $35 \pm 3.7$ points, which had no statistically significant difference $\left(\chi^{2}=0.202\right)$. The patients themselves have explained such a low estimate of psychological oppression and pessimistic predictions about the outcomes of future treatment, formed under the influence of apparently insufficient awareness about the state of health on the one hand and on the technical possibilities of treatment of this pathology on the other. Subsequently, after each course of chemotherapy between the groups of indicators, a stable difference of 16, 14 and 15 points was formed, respectively, extremely significant for the Pearson coefficient $\left(\chi^{2}>3.841\right)$, and with fluctuations within the group of $10 \pm 5 \%$.

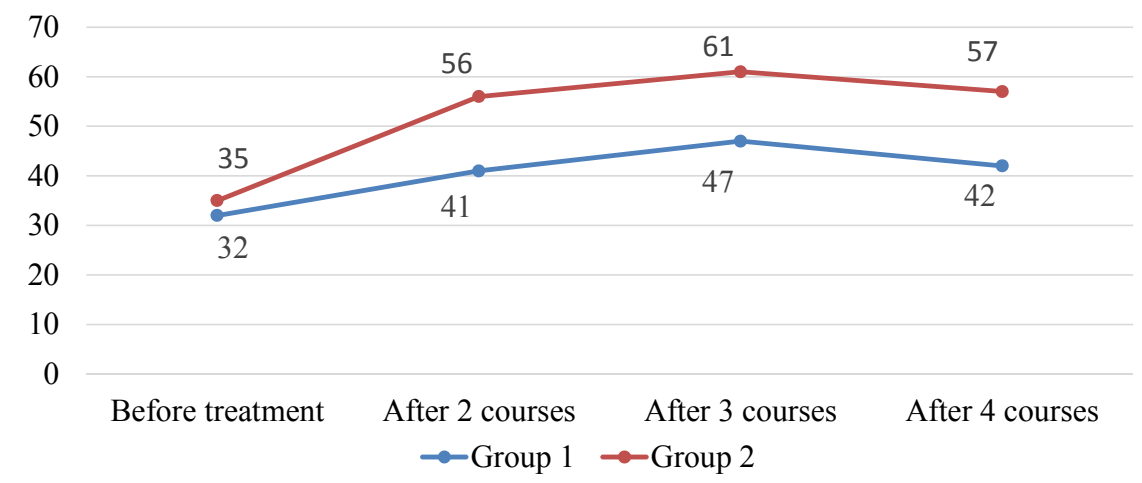

Fig. 2. Patients QH before and after SPCT and SIAPCT 


\section{Discussion}

In the structure of the EORTC QLQ-C30 questionnaire specific questions of the symptomatic scale are primarily, then there is a more general scale of functional status, at the end there are two integral indicators - quality of life and quality of health. Analyzing the questionnaires in reverse order, you can evaluate the components of these integral parameters.

The following dynamics was observed in the results of assessing the scales of general condition and physical health (Fig. 3, 4): statistically insignificant difference before the start of chemotherapy ( $63 \pm 6.4$ and $89 \pm 5.4$ points in the first group, $59 \pm 3.8$ and $90 \pm 9.6$ points in the second, $\chi^{2}$ correspondingly 0.366 and 0.053 ) with a deterioration of 5-10 points after 2 courses of PCT and further improvement in the range of 10 points in the second group and lack of dynamics in the first group. According to the authors, these two values are the key components of the integral indicator of quality of health.

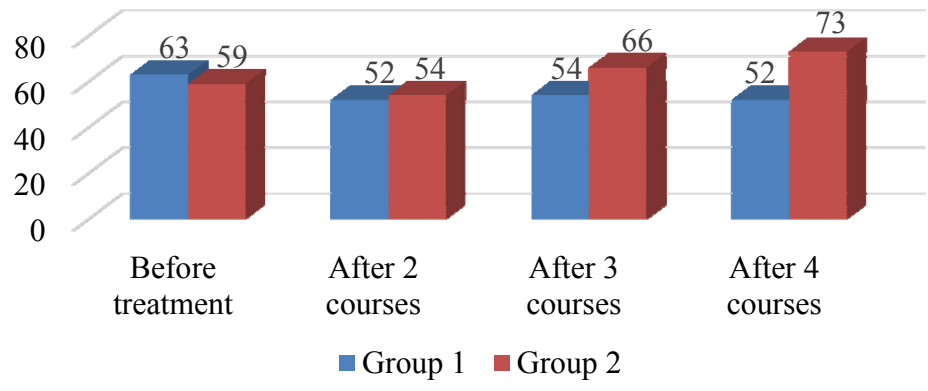

Fig. 3. General condition of patients before and after SPCT and SIAPCT

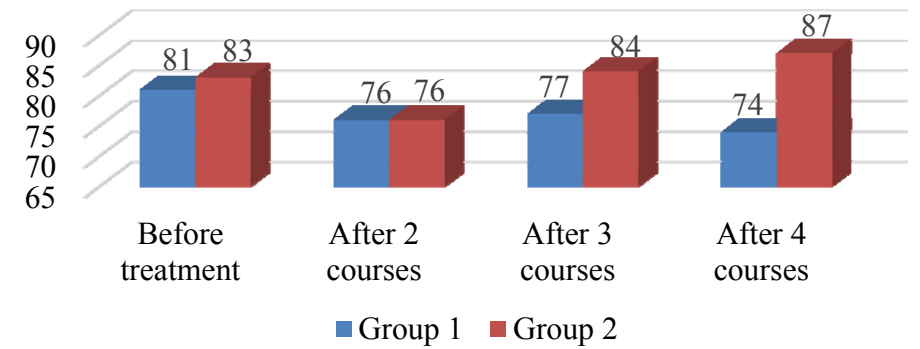

Fig. 4. Physical condition of patients before and after SPCT and SIAPCT

The least indicator of cognitive status was responded to chemotherapy: the intergroup and in-group incomplete differentials stood in the range of 10 points and did not have statistical differences (Fig. 5).

The most varied were regular indicators of the emotional state and social well-being. And if at the same time on the scale of the emotional state of change occurred unsystematically, which certainly makes this parameter the most subjective and least reliable for a separate assessment, however, as already noted, necessary for an integrated approach; then the scale of social adaptation reflects a bright positive dynamics for the second group and more moderate for the first and, according to the authors, is the most important parameter in the quality of life indicator.

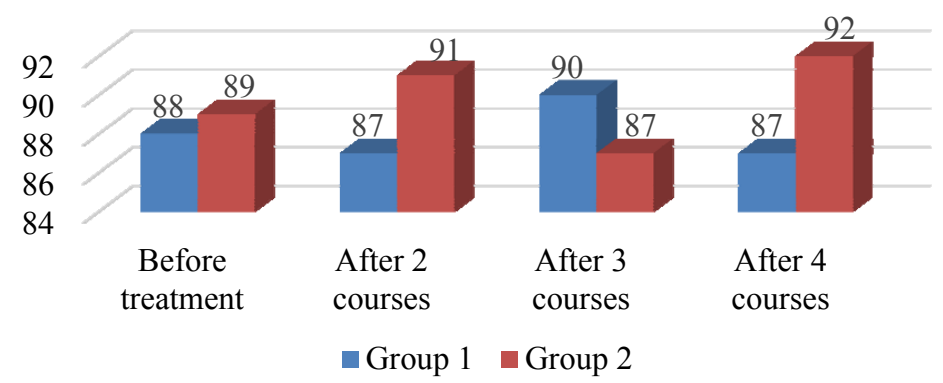

Fig. 5. Cognitive status of patients before and after SPCT and SIAPCT 
Thus, in analyzing the psychological and emotional state of women before and during chemotherapy, fluctuations of values of wide amplitude are observed without connection with external factors (Fig. 6) and is a serious consequence of insufficient professional psychotherapeutic assistance to patients.

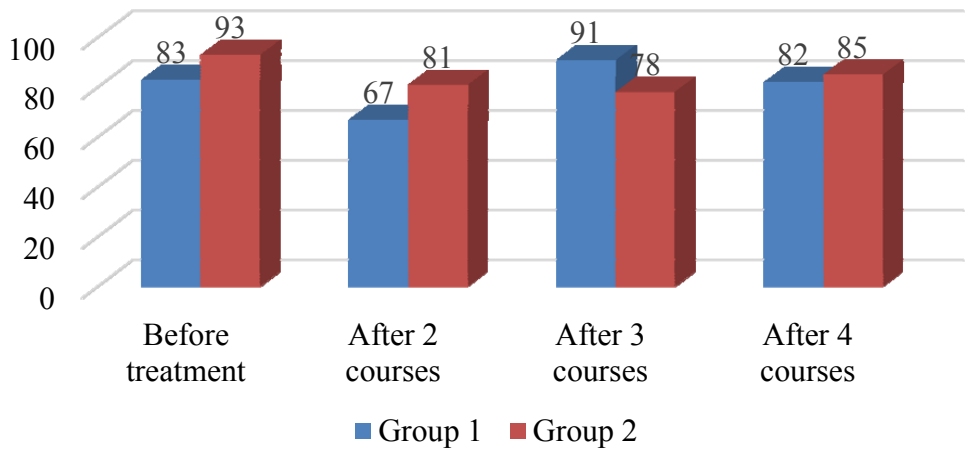

Fig. 6. Emotional state of patients before and after SPCT and SIAPCT

As already mentioned, the improvement of social adaptation (both physically due to the possibility of eliminating the potential source of tissue destruction, and morally - by depriving the patient of stigma and giving them the opportunity to return to their normal lives) and rehabilitation is the ultimate goal of comprehensive treatment and an intermediate each of the stages. In the phase of neoadjuvant therapy, the patient cannot evaluate the final result, but with the help of explanatory work the physician can correctly interpret the trends of the general state of the organism and local parameters (size and disintegration of the tumour).

Before the start of chemotherapy, patients were equally low in their social status (47士 \pm 3.7 points in the first group and $51 \pm 5.7$ in the second group). After two courses of PCT in both groups, the indicators improved: $25.5 \%$ in control patients, making $59 \pm 7.2$ points, and by $35 \%$ in the studied cohort with $69 \pm 8.9$ points.

In the following, positive dynamics was maintained (Fig. 7): in the first group $+15 \%$ (68 \pm 7.1 points) after the 3rd course and $+8.9 \%$ ( $74 \pm 4.6$ points) after the fourth; in the second $+15.9 \%$ ( $80 \pm 5.3$ points) in the third stage of the study $+7.5 \%$ ( $86 \pm 7.4$ points) in the fourth. At the same time, objectively in patients, there was a marked reduction of local symptoms in the second cohort to less pronounced in the first.

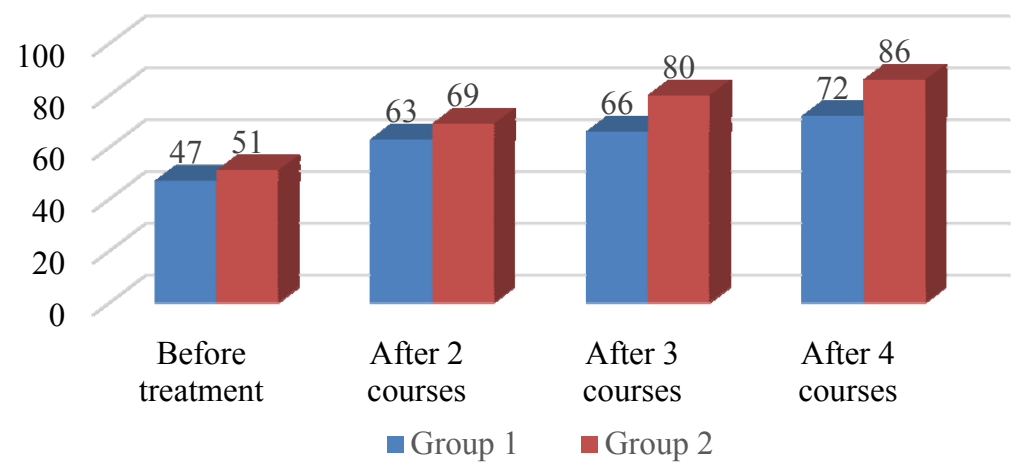

Fig. 7. Social status of patients before and after SPCT and SIAPCT

Finally, in the symptomatic panel, we chose to publish only those that had high reference values, statistical significance and pathogenetic relationship with the intervention: pain, nausea and loss of appetite - as parameters characterizing local and general changes in the body. 
Intoxication syndrome is a serious and major side effect of chemotherapeutic treatment. It is worth noting that objectively the symptoms of intoxication persist on average 5-7 days after the systemic administration of drugs and 3-5 days after regional perfusion.

Due to the rational selection of drugs for chemotherapy, intoxication does not reach the expressed scale, therefore the parameters of insomnia, apathy, depression and general fatigue will not undergo significant changes. However, as can be seen from Fig. 8, 9, nausea and loss of appetite are observed by several patients with lysis syndrome in the first stage, which on the average gives a low grade ( $13 \pm 1.4$ and $11 \pm 0.9$ points respectively in the first group, $10 \pm 0.9$ and $11 \pm 1.1$ in the second). In subsequent stages, loss of appetite and nausea was noted by almost all patients during typical time intervals and evaluated them as expressed: respectively [64 44.3 and $62 \pm 1.3$ ] points in the first group and $[45 \pm 5.1$ and $44 \pm 1.0]$ points in the second to the second at the stage [ $58 \pm 5.3$ and $57 \pm 0.4]$ and $[41 \pm 6.5$ and $37 \pm 1.4$ ], respectively, in the third; [ $49 \pm 5.7$ and $51 \pm 1.3$ ] and [ $38 \pm 7.0$ and $30 \pm 1.1]$ on the fourth. In the analysis, there was a significant difference between the parameters at each of the stages, which determines the priority of regional chemotherapy before the system in the context of treatment of LA BC.

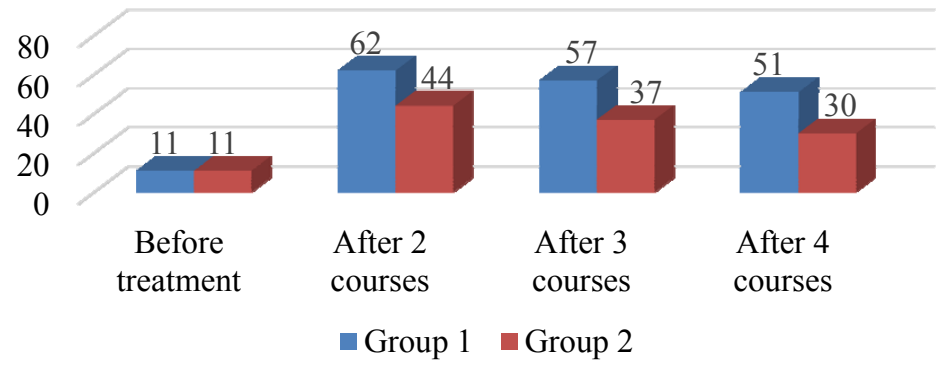

Fig. 8. Loss of appetite in patients before and after SPCT and SIAPCT

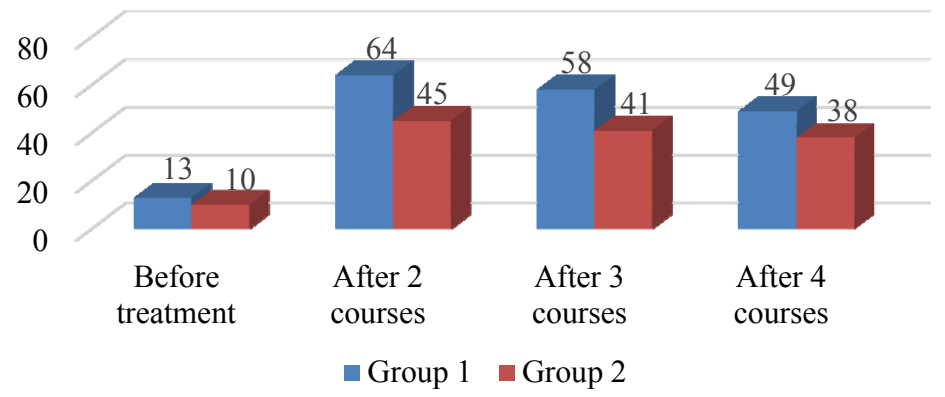

Fig. 9. Nausea in patients before and after SPCT and SIAPCT

Particular attention deserves the parameter of pain. In general, it reflects the dynamics of the local process, and therefore correlates with the system to achieve clinical effect (resectability of the tumour) and almost does not differ between the groups (Fig. 10).

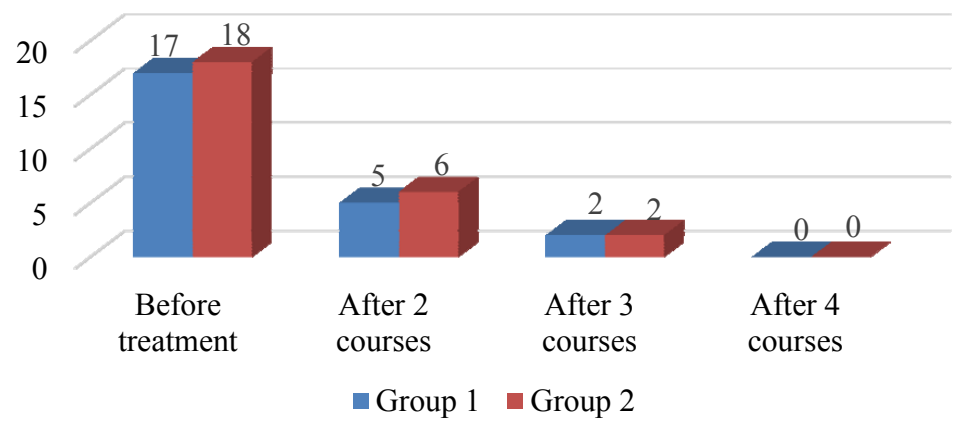

Fig. 10. Pain in patients before and after SPCT and SIAPCT 


\section{Results}

1. After the research, the range of the quality of life indicator in patients with inoperable forms of LA BC before and after neoadjuvant courses of systemic polychemotherapy (SPCT) and selective intra-arterial polychemotherapy (SIAPCT) was determined.

2. The value of including the assessment of quality of life as an important element of an important research, which allows to improve the quality of scientific work, is clarified.

3. It has been determined that QL is a reliable, informative and economical method for assessing the health of the patient both at the group and at the individual level. In cancer studies, the evaluation of QL is an important criterion for assessing the effectiveness of treatment and has a prognostic value.

4. The assessment of quality of life in clinical trials improves the quality of the study itself.

\section{References}

[1] Aksel, E. M. (2006). Zlokachestvennyie novoobrazovaniya molochnoy zhelezyi: sostoianie onkologicheskoy pomoschi, zabolevaemost i smertnost. Mammologiya, 1, 9-13.

[2] Putyrskiy, L. A., Putyrskogo, Yu. L. (Eds.) (2008). Dobrokachestvennyye i zlokachestvennyye zabolevaniya molochnoy zhelezy. Moscow: Meditsinskoye informatsionnoye agentstvo, 336.

[3] Gantsev, Sh. Kh. (2015). Rak molochnoy zhelezy. Rukovodstvo dlya vrachey. Moscow: GEOTAR-Media, 142.

[4] Shivilov, E. (2011). Rak Molochnoy Zhelezy. Moscow: LAP Lambert Academic Publishing, 200.

[5] Cherenkov, V., Tverezovskiy, S., Petrov, A. (2013). Opukholi molochnoy zhelezy. Moscow: LAP Lambert Academic Publishing, 168.

[6] Khaylenko, V. A., Komov, D. V. (2015). Onkomammologiya. Moscow: MEDpress-inform, 328.

[7] Chen, U. I., Uordli, E. (Eds.) (2009). Rak molochnoy zhelezy. Moscow: Rid Elsiver, 208.

[8] Kit, O. I., Gevorkyan, Yu. A., Soldatkina, N. V. (2011). Organosokhranyayushcheye lechenye raka molochnoy zhelezy. Moscow: LAP Lambert Academic Publishing, 400.

[9] Aleksey, V. (2012). Organosokhranyayushcheye lecheniye bolnykh rakom molochnoy zhelezy. Moscow: LAP Lambert Academic Publishing, 136.

[10] Kuklin, I. (2012). Optimizatsiya khirurgicheskogo lecheniya pri opukholyakh molochnoy zhelezy. Moscow: LAP Lambert Academic Publishing, 208.

[11] Shalimova, S. O. (Eds.) (2012). Rak v Ukrayini, 2010-2011. Zahvoryuvanist, smertnist, pokazniki diyainosti onkologichnoiy sluzhbi. Biuleten natsionalnogo kantser-reestru Ukraiyini. Kyiv, No. 13, 51.

[12] Davydov, M. I., Gantsev, Sh. Kh. (2013). Onkologiya. Moscow: GEOTAR-Media, 920.

[13] Ionova, T. I., Novik, A. A., Suhonos, Yu. A. (1998). Kachestvo zhizni onkologicheskih bolnyih. Voprosi onkologii, 44 (6), 749-752.

[14] Novik, A. A., Ionova, T. I., Kaynd, P. (1999). Kontseptsiya issledovaniya kachestva zhizni v meditsine. Sankt-Peterburg: Elbi, 140.

[15] Tarabrina, N. V., Vorona, O. A., Kurchakova, M. S., Padun, M. A., Shatalova, N. E. (2010). Onkopsikhologiya. Moscow: Institut psikhologii RAN, 176.

[16] Laktionov, K. P., Blokhin, S. N. (2008). Rekonstruktivnyye operatsii pri rake molochnoy zhelezy. Moscow: GEOTAR-Media, 128.

[17] Semiglazov, V. F., Semiglazov, V. V., Kletsel, A. E. (2008). Neoadyuvantnoye i adyuvantnoye lecheniye raka molochnoy zhelezy. Moscow: Meditsinskoye informatsionnoye agentstvo, 288.

[18] Gabka, K. Dzh., Bomert, K. (2010). Plasticheskaya i rekonstruktivnaya khirurgiya molochnoy zhelezy. Moscow: MEDpress-inform, 360.

[19] Semiglazov, V. F., Semiglazov, V. V. (2014). Rak molochnoy zhelezy. Biologiya. mestnoye i sistemnoye lecheniye. Moscow: Spetsialnoye izdatelstvo meditsinskikh knig, 352.

[20] Sedakov, I. E. (2004). Morfologichni kriteriy diagnostiki, otsinka efektivnosti i prognoz pri kombinovanomu likuvanni mistsevo poshirenogo pervinno neoperabelnogo raku molochnoiy zalozi. Ukr. med. almanah, 7 (3), 133-137.

[21] Bondar, A. V., Sedakov, I. E., Shlopov, V. G. (2005). Pervinno neoperabelniy rak molochnoiyi zalozi. Donetsk: Kashtan, 348. 